\title{
Chronic thromboembolic pulmonary hypertension as a cause of dyspnoea in an older patient with a complex history
}

\author{
C.M. Kähler
}

ABSTRACT: A full diagnostic work-up for patients with pulmonary hypertension (PH) is vital. Classification and diagnosis of the underlying cause is important to ensure optimal management, but may be complicated by overlapping signs and symptoms. This case study describes how a full work-up identified chronic thromboembolic PH (CTEPH) as the cause of dyspnoea in a 68-yr-old male with a history of pulmonary embolism and an original diagnosis of chronic obstructive pulmonary disease. Key indicators included decreased tricuspid annular plane systolic excursion, increased Tei index and elevated systolic pulmonary artery pressure. Multi-slice spiral chest computed tomography and pulmonary angiography showed severe chronic thromboembolic pulmonary disease, both centrally and distally. Diffusing capacity of the lung for carbon monoxide was reduced and blood gas analysis revealed a wide alveolar-arterial oxygen pressure difference, which is typical of CTEPH. The patient was eligible for pulmonary endarterectomy according to established criteria. Residual PH after surgery was successfully managed with bosentan.

KEYWORDS: Chronic thromboembolic pulmonary hypertension, dyspnoea, pulmonary hypertension

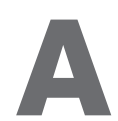
64-yr-old male first presented in 2003 at a local chest hospital with exertional dyspnoea, following a pulmonary embolism in 2002 and a history of smoking. At that time, a computed tomography (CT) scan revealed pulmonary embolism mainly in the left lower lobe; transthoracic echocardiography showed a slightly reduced left ventricular ejection fraction (EF) and elevated pulmonary arterial pressure (Ppa) (table 1). He was hypoxic and hyperventilating, with low oxygen saturation. The patient was diagnosed with chronic obstructive pulmonary disease with hypoxaemia, and discharged; congestive heart failure was attributed to the low $\mathrm{EF}$ and the prior history of pulmonary embolism. Acenocoumarol, ramipril, carvedilol, oxygen and salbutamol were started. In 2007, he presented again at another local hospital with worsening dyspnoea; investigations showed increased $P$ pa, with similar EF and lung function to those at the first assessment (table 1).

The patient was subsequently reinvestigated by a specialist pneumology unit. Transthoracic echocardiography revealed decreased tricuspid annular plane systolic excursion (TAPSE; $1.4 \mathrm{~cm}$ ) with increased Tei index (1.61) and increased right atrial and ventricular dimensions, with estimated systolic $P$ pa of $70 \mathrm{mmHg}$ (fig. 1). At this stage, forced vital capacity was $90 \%$ predicted, forced expiratory volume in $1 \mathrm{~s}$ was $76 \%$ pred (a ratio of $69 \%$ ) and peak expiratory flow was 70\% pred. Lung function tests and CT excluded emphysema, with normal total lung capacity and residual volume, and no hyperinflation. The patient's 6-min walk distance (6MWD) was $384 \mathrm{~m}$. However, the diffusing capacity of the lung for carbon monoxide was reduced ( $59 \%$ ), as is the case in $\sim 20 \%$ of patients with idiopathic pulmonary arterial hypertension or chronic thromboembolic pulmonary hypertension (CTEPH) [1, 2]. Multi-slice spiral chest CT and pulmonary angiography showed severe chronic thromboembolic pulmonary disease, both centrally and distally (fig. 2). Doppler ultrasound revealed thrombosis of the vena poplitea up to the vena saphena magna on the left. Other investigations, including autoimmunity, sleep apnoea and HIV tests, were negative, although there was slight congestive hepatopathy. The patient was still hypoxic (arterial oxygen tension $56.4 \mathrm{mmHg}$ ) and hyperventilating (arterial carbon dioxide tension
CORRESPONDENCE C.M. Kähler

Pneumology/USPH Innsbruck, Internal Medicine I,

Dept of Internal Medicine Medical University of Innsbruck (MUI)

Anichstrasse 35 6020 Innsbruck Austria

E-mail: C.M.Kaehler@i-med.ac.at

Received:

June 012009

Accepted after revision:

June 122009

PROVENANCE

Publication of this peer-reviewed article was supported by Actelion Pharmaceuticals Ltd, Switzerland (unrestricted grant, European Respiratory Review issue 113). 


\begin{tabular}{|c|c|c|}
\hline \multirow[t]{2}{*}{ TABLE 1} & \multicolumn{2}{|c|}{$\begin{array}{l}\text { Initial and secondary assessment prior to referral } \\
\text { to specialist unit }\end{array}$} \\
\hline & Initial assessment & Second assessment \\
\hline \multicolumn{3}{|c|}{ Echocardiography } \\
\hline EF \% & 45 & 50 \\
\hline TR grade & $\|$ & $\|$ \\
\hline Ppa $\mathrm{mmHg}$ & 45 & 70 \\
\hline \multicolumn{3}{|l|}{ Lung function } \\
\hline FVC \% pred & 85 & 85 \\
\hline FEV $1 \%$ pred & 78 & 72 \\
\hline $\mathrm{FEV}_{1} / \mathrm{FVC} \%$ & 69 & 69 \\
\hline PEF \% pred & 46 & 66 \\
\hline $\mathrm{Pa}, \mathrm{O}_{2} \mathrm{mmHg}$ & 54.1 & 57.5 \\
\hline $\mathrm{Pa}_{1} \mathrm{CO}_{2} \mathrm{mmHg}$ & 30.9 & 30.6 \\
\hline $\mathrm{pH}$ & 7.42 & 7.41 \\
\hline $\mathrm{O}_{2} \%$ & 88 & 89 \\
\hline
\end{tabular}

EF: ejection fraction; TR: tricuspid regurgitation; Ppa: pulmonary artery pressure; FVC: forced vital capacity; \% pred: \% predicted; FEV1: forced expiratory volume in $1 \mathrm{~s}$; PEF: peak expiratory flow; $\mathrm{Pa}, \mathrm{O}_{2}$ : arterial oxygen tension; $\mathrm{Pa}_{\mathrm{a}} \mathrm{CO}_{2}$ : arterial carbon dioxide tension.

$30.2 \mathrm{mmHg}$ ), with low oxygen saturation (89\%) and blood $\mathrm{pH}$ of 7.41. Blood gas analysis revealed a wide alveolar-arterial oxygen tension difference of $45.2 \mathrm{mmHg}$, which is typical for patients with CTEPH [3]. Diagnosis was supported by right heart catheterisation (table 2).

The patient met the established criteria for pulmonary endarterectomy [4], including mean $P$ pa $\geqslant 25 \mathrm{mmHg}$, $\geqslant 3$ months of

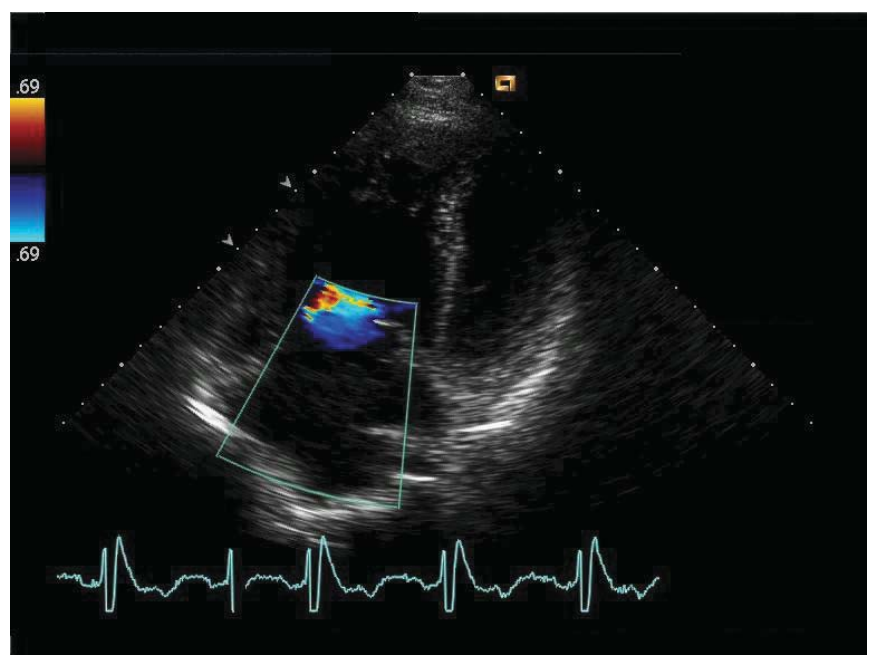

FIGURE 1. Echocardiography image obtained during investigation by the specialist pneumology unit.

effective oral anticoagulation, evidence of surgically accessible thrombi, a beneficial relationship between pulmonary vascular resistance (PVR) and the anticipated thrombus mass, no comorbidities and no severe reduction in lung function. At $1,200 \mathrm{dyn} \cdot \mathrm{s} \cdot \mathrm{cm}^{-5}$, PVR was slightly higher than optimal (recommended $<1,000 \mathrm{dyn} \cdot \mathrm{s} \cdot \mathrm{cm}^{-5}$ ). The surgery was successful, and therapies including phenprocoumon, carvedilol, furosemide and salbutamol were started. Following surgery, N-terminal pro-brain natriuretic peptide concentrations declined from $\sim 5,000$ to $1,000 \mathrm{ng} \cdot \mathrm{L}^{-1}$, and 6MWD increased to $479 \mathrm{~m}$, with an improvement in World Health Organization functional class (from III to II).
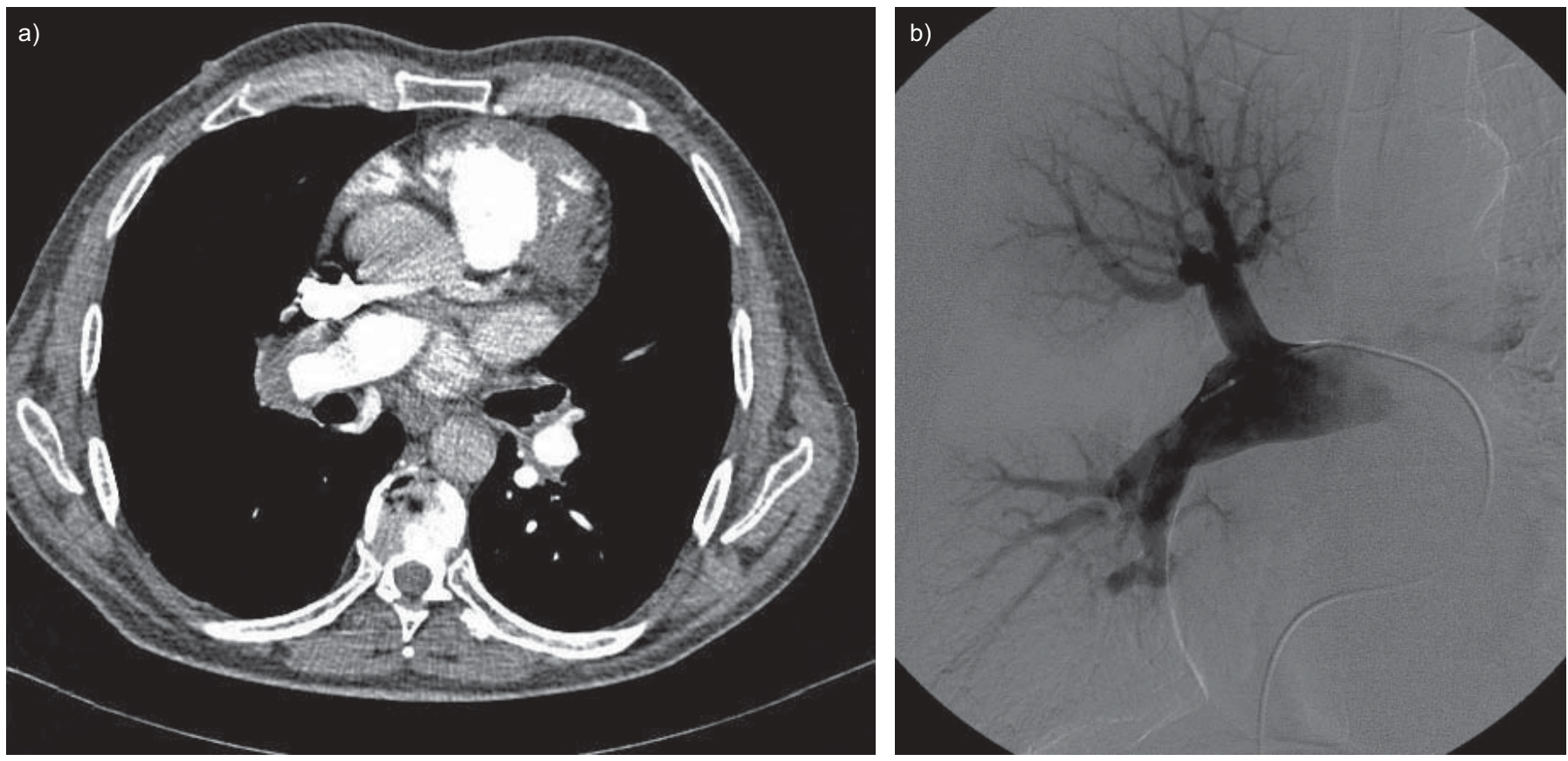

FIGURE 2. a) Multi-slice spiral chest computed tomography scan and b) pulmonary arterial angiography at diagnosis of chronic thromboembolic pulmonary hypertension. 


\begin{tabular}{lc} 
TABLE 2 & $\begin{array}{l}\text { Right heart catheterisation at diagnosis of chronic } \\
\text { thromboembolic pulmonary hypertension }\end{array}$ \\
Parameter & Value \\
\hline Ppa $\mathbf{~ m m H g}$ & 58 \\
Prv $\mathbf{~ m H g}$ & 26 \\
Pra $\mathbf{~ m H g}$ & 20 \\
$\bar{P}_{\text {pcw } \mathbf{~ m m H g}}$ & 14 \\
PVR dyn $\mathbf{s} \cdot \mathbf{c m}^{-\mathbf{5}}$ & 1200 \\
Cardiac output & 2.2 \\
\hline
\end{tabular}

$\bar{P}$ pa: mean pulmonary artery pressure; Prv: right ventricular pressure; Pra: right atrial pressure; $\bar{P}_{\text {pcw: }}$ mean pulmonary capillary wedge pressure; PVR: pulmonary vascular resistance. ${ }^{*}$ : measured using the Fick method.

However, although the surgery reduced mean $P$ pa (from 61 to $44 \mathrm{mmHg}$ ), it was still higher than that of the normal population, as was PVR (reduced from 1,200 to $514 \mathrm{dyn} \cdot \mathrm{s} \cdot \mathrm{cm}^{-5}$ ). Similarly, the Tei index, although reduced from 1.61 to 0.67 , was not within the normal range $(\leqslant 0.4)$, and TAPSE was still abnormal $(\leqslant 2 \mathrm{~cm})$, having changed little from 1.4 to $1.3 \mathrm{~cm}$. This indicated that, despite the surgery, there was residual pulmonary hypertension (PH) (fig. 3). To decrease the pulmonary pressure further, treatment with bosentan was initiated on a compassionate use basis and titrated to a final dose of $125 \mathrm{mg}$ b.i.d. An increase in TAPSE (from 1.3 to $1.8 \mathrm{~cm}$; approaching normal) and a decrease in Tei index (from 0.67 to 0.5 ; approaching normal) were observed following bosentan treatment. There was also a further improvement in 6MWD to $517 \mathrm{~m}$. No further invasive assessments of haemodynamics were performed.

\section{DISCUSSION}

This case emphasises the importance of a full diagnostic workup for patients with $\mathrm{PH}$. Classification and diagnosis of the underlying cause of $\mathrm{PH}$ [5] is important, in order to ensure optimal management, but may be complicated by overlapping signs and symptoms. While dyspnoea is a common clinical finding in $\mathrm{PH}$, it is nonspecific; therefore, a correct diagnosis of patients presenting with breathlessness relies on a full diagnostic work-up. Echocardiography is a useful noninvasive technique in this respect, allowing estimation of baseline and follow-up $P$ pa, tricuspid regurgitation, and atrial and ventricular size and function. However, the correlation between calculated $P$ pa by echocardiography and that measured by right heart catheterisation is reported to be poor [6,7]. TAPSE and Tei index are useful parameters of right ventricular function in pulmonary arterial hypertension (PAH) and assessment of these may be more accurate than echocardiography-calculated $P$ pa alone [8]. In addition, TAPSE and Tei index are predictors of survival [9, 10] and may, therefore, be more useful for assessing treatment responses than calculated $P$ pa alone.

The occurrence of CTEPH after a diagnosis of acute pulmonary embolism, although rare, is more common than previously thought, being estimated at $3.8 \%$ of all patients surviving an episode of symptomatic idiopathic pulmonary embolism within 2 yrs [11]. Depending on established eligibility criteria, pulmonary endarterectomy is the preferred approach for CTEPH patients, and may restore haemodynamics in $80 \%$ of cases [4]. However, as illustrated here, surgery does not always correct the $\mathrm{PH}$; in a recent UK study, 35\% of 198 patients had mean $P$ pa $>25 \mathrm{mmHg}$ and PVR $>240 \mathrm{dyn} \cdot \mathrm{s} \cdot \mathrm{cm}^{-5}$ after surgery [12]. Residual PH is the most important determinant of postendarterectomy outcome, being associated with decreased survival [8]. In the UK study, patients who survived to 3 months after surgery, but had persistent $\mathrm{PH}$, had a 3-yr survival of $94 \%$ [12]. In such cases of persistent $\mathrm{PH}$, management options are currently limited; in a UK cohort, $18 \%$ of patients with persistent disease already received PAH-modifying therapies [12].

In this case study, the post-surgical residual PH was successfully treated with bosentan. Bosentan has previously shown promise for CTEPH patients, including those considered unsuitable for surgery and cases that have residual $\mathrm{PH}$ after surgery [13-16]. The response of the current patient also

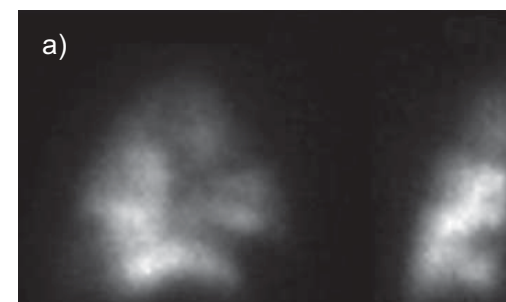

Right lateral

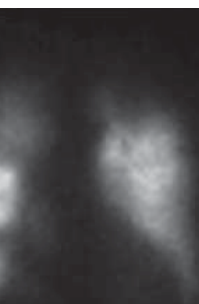

Anterior

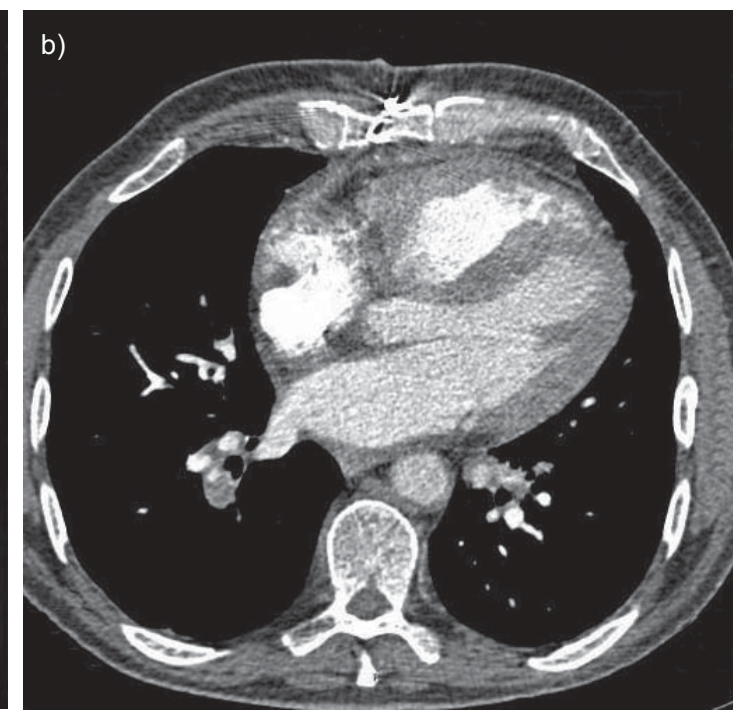

FIGURE 3. a) Lung perfusion (seated patient) and b) high-resolution computed tomography scans obtained after pulmonary endarterectomy. 
suggests that bosentan may be of use for $\mathrm{PH}$ that persists despite surgery.

\section{Conclusions}

A full diagnostic work-up is required for patients with $\mathrm{PH}$. Of those with CTEPH, candidates for pulmonary endarterectomy should be assessed against current eligibility criteria. The optimal management of inoperable cases of CTEPH is under evaluation and there are limited data describing the treatment of residual $\mathrm{PH}$ after surgery; however, there may be beneficial effects of novel targeted therapies, and further research is needed.

\section{STATEMENT OF INTEREST}

C.M. Kähler has received honoraria for speaking or serving on advisory boards from Actelion, Pfizer, Bayer Schering, Encysive and AOP. The author is further supported by unrestricted research grants from Actelion, Encysive and AOP, and has received funds from Actelion, Pfizer, Bayer Schering, Encysive and AOP for members of staff and received consultancy fees from Actelion. C.M. Kähler has acted as an expert witness on the subject.

\section{ACKNOWLEDGEMENTS}

The author would like to thank Elements Communications Ltd (Westerham, UK) for providing medical writing assistance supported by Actelion Pharmaceuticals Ltd (Allschwil, Switzerland).

\section{REFERENCES}

1 Burke CM, Glanville AR, Morris AJ, et al. Pulmonary function in advanced pulmonary hypertension. Thorax 1987; 42: 131-135.

2 Steenhuis LH, Groen HJ, Koëter GH, et al. Diffusion capacity and haemodynamics in primary and chronic thromboembolic pulmonary hypertension. Eur Respir J 2000; 16: 276-281.

3 Oswald-Mammosser M, Albert RK, Weitzenblum E, et al. $\mathrm{AaDO}_{2}$ as a predictor of pulmonary hypertension resulting from pulmonary emboli. Cor Vasa 1991; 33: 235-243.

4 Lang IM, Klepetko W. Chronic thromboembolic pulmonary hypertension: an updated review. Curr Opin Cardiol 2008; 23: 555-559.
5 Simonneau G, Galiè N, Rubin LJ, et al. Clinical classification of pulmonary hypertension. J Am Coll Cardiol 2004; 43: Suppl. S, 5S-12S.

6 Barst RJ, McGoon M, Torbicki A, et al. Diagnosis and differential assessment of pulmonary arterial hypertension. J Am Coll Cardiol 2004; 43: 40S-47S.

7 Fisher MR, Forfia PR, Chamera E, et al. Accuracy of Doppler echocardiography in the hemodynamic assessment of pulmonary hypertension. Am J Respir Crit Care Med 2009; 179: 615-621.

8 Vonk MC, Sander MH, van den Hoogen FH, et al. Right ventricle Tei-index: a tool to increase the accuracy of non-invasive detection of pulmonary arterial hypertension in connective tissue diseases. Eur J Echocardiogr 2007; 8: 317-321.

9 Yeo TC, Dujardin KS, Tei C, et al. Value of a Doppler-derived index combining systolic and diastolic time intervals in predicting outcome in primary pulmonary hypertension. Am J Cardiol 1998; 81: 1157-1161.

10 Ghio S, Klersy C, Magrini G, et al. Prognostic relevance of the echocardiographic assessment of right ventricular function in patients with idiopathic pulmonary arterial hypertension. Int $J$ Cardiol 2008; [Epub ahead of print PMID: 19070379].

11 Pengo V, Lensing $\mathrm{AW}$, Prins $\mathrm{MH}$, et al. Incidence of chronic thromboembolic pulmonary hypertension after pulmonary embolism. N Engl J Med 2004; 350: 2257-2264.

12 Condliffe R, Kiely DG, Gibbs JS, et al. Improved outcomes in medically and surgically treated chronic thromboembolic pulmonary hypertension. Am J Respir Crit Care Med 2008; 177: 1122-1127.

13 Mellemkjaer S, Ilkjaer LB, Klaaborg KE, et al. Pulmonary endarterectomy for chronic thromboembolic pulmonary hypertension. Ten years experience in Denmark. Scand Cardiovasc J 2006; 40: 49-53.

14 Vassallo FG, Kodric M, Scarduelli C, et al. Bosentan for patients with chronic thromboembolic pulmonary hypertension. Eur J Intern Med 2009; 20: 24-29.

15 Jaïs X, D'Armini AM, Jansa $P$, et al. Bosentan for treatment of inoperable chronic thromboembolic pulmonary hypertension: BENEFiT (Bosentan Effects in inoperable Forms of chronic Thromboembolic pulmonary hypertension), a randomized, placebo-controlled trial. J Am Coll Cardiol 2008; 52: 2127-2134.

16 Hughes RJ, Jais X, Bonderman D, et al. The efficacy of bosentan in inoperable chronic thromboembolic pulmonary hypertension: a 1year follow-up study. Eur Respir J 2006; 28: 138-143. 